\title{
PAPO NEGÓCIO
}

Thiago José de Azevêdo Loureiro ${ }^{1}$

Leandro da Cruz Martins ${ }^{2}$

\section{RESUMO}

O Projeto de Extensão "Papo de Negócio" é realizado por intermédio de palestras para empresários, empreendedores e comerciantes da Região Agreste do Rio Grande do Norte. Essas palestras acontecem bimestralmente, nas quais são abordados diversos temas que contribuem para o desenvolvimento dos negócios, tendo em vista ser essencial, no mundo globalizado, dinâmico e competitivo que os empresários atualizem-se e adquiriram conhecimentos constantemente, contribuindo assim, para o crescimento e fortalecimento de suas empresas e consequentemente da Região. É importante salientar que os palestrantes sugerem 3 (três) temas, sendo escolhido 1 (um) pelos participantes para a palestra seguinte.

Palavras-chave: Conhecimento. Desenvolvimento de negócios. Empresa.

\section{INTRODUÇÃO}

É incontestável que, no mundo globalizado em que vivemos, as empresas realizam um grande papel para o desenvolvimento sustentável da sociedade por meio da criação, divulgação e oferta de produtos e/ou serviços que atendam às necessidades e desejos das pessoas e da oferta de vagas de trabalho/emprego o que proporciona geração de renda e dignifica o indivíduo como cidadão.

Conforme dados de um estudo, denominado Demografia das Empresas, realizado em 2012 pelo Instituto Brasileiro de Geografia e Estatística (IBGE), 45\% das empresas brasileiras encerram suas atividades em menos de dois anos de funcionamento em virtude dá falta de gestão organizacional eficiente.

Considerando que o Instituto Federal de Educação, Ciência e Tecnologia do Rio Grande do Norte (IFRN) é uma Instituição de Ensino, Pesquisa e Extensão de referência no país, no que se refere à capacitação de profissionais para o mercado de trabalho, surgiu, no Campus Nova Cruz/RN, o interesse em realizar um Projeto de Extensão para contribuir com a longevidade dos negócios da Região Agreste do Rio Grande do Norte, denominado Papo de Negócio.

Para o IFRN, o projeto também é importante por promover parcerias, divulgar suas ações de Ensino, Pesquisa e Extensão, facilitando a inserção de seus discentes e egressos no mercado de trabalho, seja através de estágios ou contratações efetivas.

\section{DESENVOLVIMENTO}

O "Papo de negócio" acontece de forma bimestral por meio de palestras sobre temas de interesse dos proprietários e/ou gerentes dos

1 Professor do Campus Nova Cruz, graduado em administração e mestre em engenharia da produção.

2 Aluno do curso técnico integrado em informática do Campus Nova Cruz. 
negócios da região Agreste. Ao final de cada "papo" é apresentada uma ferramenta de fácil utilização e baixo custo que pode ser aplicada nas empresas a fim de qualificar seus processos.

A divulgação do primeiro Papo de Negócio ocorreu através do Facebook e site institucional, blogs e rádios da região e, principalmente, através de 250 convites entregues aos próprios empresários. Na entrega dos convites os alunos fizeram uma breve explanação sobre o que o evento, como iria ocorrer e de que forma ele poderia contribuir para uma melhor gestão de suas empresas.

O primeiro "Papo de negócio" (figuras 1 e 2) aconteceu no dia 21 de maio de 2014 reunindo aproximadamente 60 empresários da região; o tema abordado foi "Gestão de Pessoas".

O professor do curso técnico de nível médio em administração, Thiago José de Azevêdo Loureiro, proferiu a palestra "Como ter uma equipe comprometida", ao final, apresentou aos participantes a ferramenta "Diário de bordo" que proporciona aos colaboradores organizar diariamente suas tarefas e aos gestores monitorar e futuramente avaliar cada colaborador.

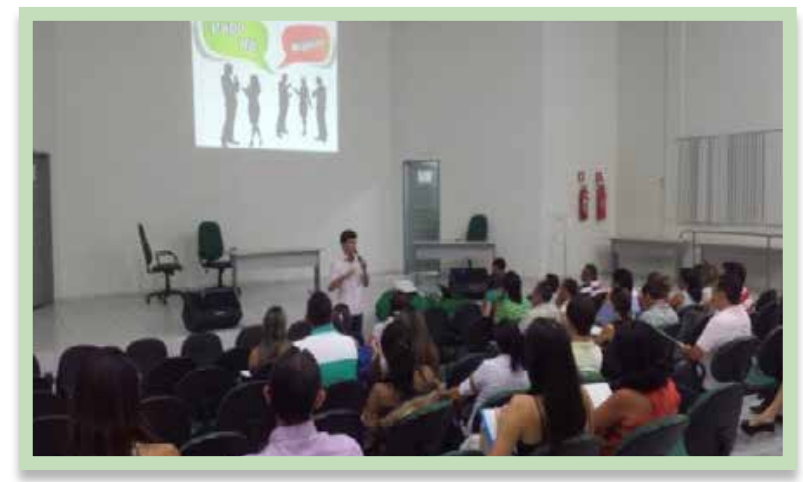

Figura 1: apresentação o projeto

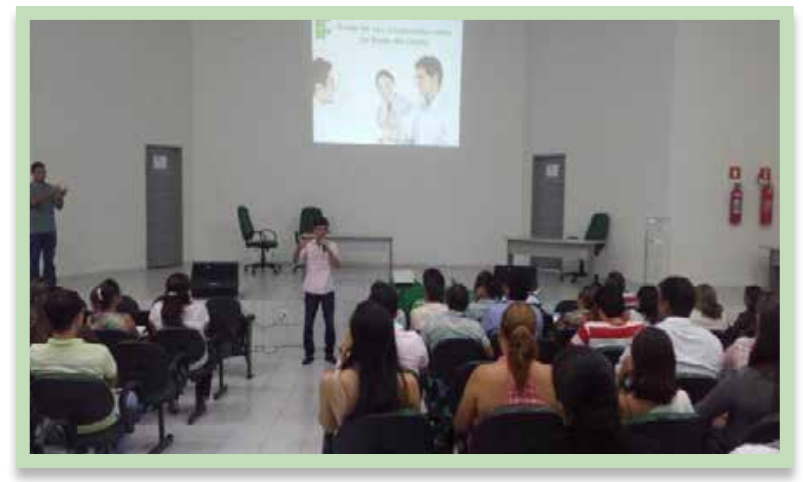

Figura 2: discutindo sobre o tema abordado

Ao término da palestra, percebeu-se que o evento proporcionou resultados positivos, tendo em vista que os empresários mostraram- se interessados em participar/interagir e houve a formalização de 14 Termos de Convênios de Estágios.

No dia 23 de Julho de 2014, realizou-se a segunda palestra com o tema "A importância dos Sistemas de Informação na Gestão da sua Empresa", reunindo aproximadamente 35 empresários.

A palestra (figuras 3 e 4) foi proferida pela professora do Curso Técnico de Nível Médio em Informática, Tatiana Amaral Sorrentino, que explanou sobre a importância e benefícios dos sistemas de informação para o desenvolvimento dos negócios.

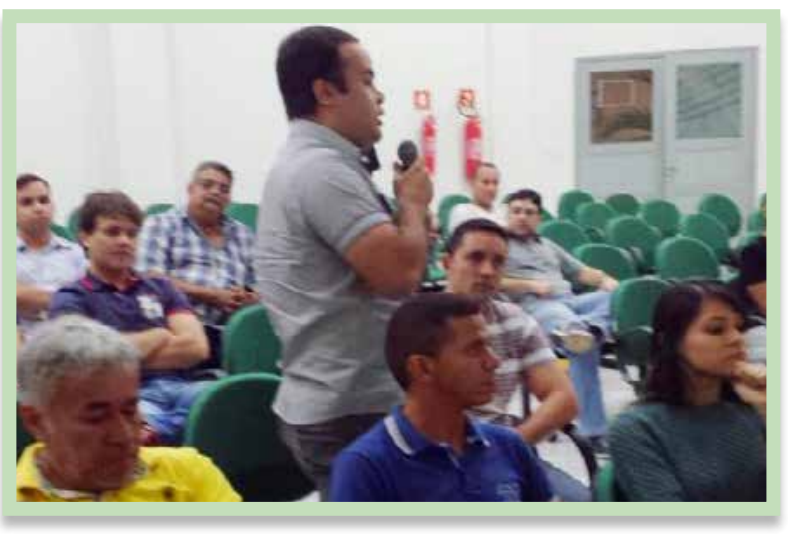

Figura 3: prorietário da Controle Informática.

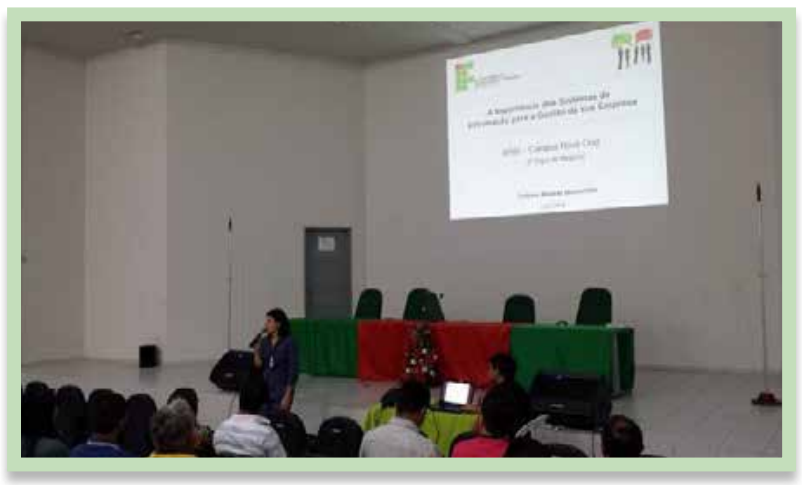

Figura 4: segunda palestra do Papo de Negócio

Nesse segundo "papo" um aspecto bastante positivo foi a excelente interação dos empresários, o que contribui e enriqueceu o encontro. Ao final, o tema escolhido para o terceiro "Papo de Negócio" foi "Qualidade nos Serviços". O evento acontecerá em setembro de 2014.

\section{CONCLUSÃO}

É importante destacar que, de um modo geral, os empresários da região Agreste ainda não perceberam a importância do IFRN para seus negócios, um fato que atesta isso são os eventos 
organizados anteriormente pela Coordenação de Extensão, nos quais o número de participantes sempre foi inferior a dez pessoas.

Sendo assim, entende-se que, em pouco tempo de execução, aproximadamente três meses, o Projeto de Extensão "Papo de Negócio", já obteve resultados bastante positivos. $O$ número de participantes nos dois primeiros encontros foi de quase 100 (cem) empresários. $O$ projeto a cada dia passa a ser mais comentado na região, o número de Termos de Convênios de Estágio firmados é significativo e a interação dos presentes no segundo "papo" foi bem maior do que no primeiro.

Portanto, o projeto vem cumprindo seu objetivo, que é estreitar e fortalecer a relação do IFRN com a sociedade, proporcionando crescimento mútuo e facilitando o acesso dos discentes ao mercado de trabalho.

\section{REFERENCIAS}

SEBRAE. $\mathbf{4 8 \%}$ das empresas brasileiras fecham as portas depois de três anos. Paraná: [s.n], 2012. Disponível em: < http://www.sebraepr. com.br/ Portallnternet /Noticia/ci.48\%25-dasempresas- brasileiras -fecham-as-portas-depoisde-tr\%C3\%AAs-anos.print >. Acesso em: 20 jul. 2014. 